\title{
Why is a Raven Like a Writing Desk?
}

\section{By Karen Green}

Friday August 7, 2009 09:00:00 am

Our columnists are independent writers who choose subjects and write without editorial input from comiXology. The opinions expressed are the columnist's, and do not represent the opinion of comiXology.

Why is a Raven Like a Writing Desk?

When I was in the seventh grade, my English teacher read "Jabberwocky" to us. The thing is, she mispronounced "slithy." She pronounced it as if related to "slither," but I knew it was supposed to be pronounced "sly-thee." And the reason I knew this was that, a year or two earlier, my brother, in one of his then-frequent bursts of inspired gift-buying, had bought me Martin Gardner's The Annotated Alice, which I had read through rapaciously and repeatedly. The next day, I discreetly brought a copy of Webster's Dictionary, with its pronunciation guide, and my copy of The Annotated Alice to my teacher's desk before class began. I showed her how Gardner had included Lewis Carroll's own description of how to pronounce his Jabberwocky neologisms. She looked up at me and snarled, "Listen! I don't need any half-pint pipsqueak to tell me how to do my job!" I received lousy grades in English for the rest of the year.

Hey! Mrs Pantuso of Fort Lee (NJ) Intermediate School (1971)! How d'you like me now??

\section{Ahem.}

I relate this [bitter] anecdote to demonstrate my bona fides re immersion in the Carrollingian world, starting at a very young age. I'd discovered the Alice books when I was 8 or 9 years old, delved into their Victorian context in Gardner's book at the age of 11 or 12, and bought The Complete Lewis Carrolffor a cross-country bus trip when I was 17. I mean, I've read Sylvie and Bruno, people. BOTH VOLUMES. 


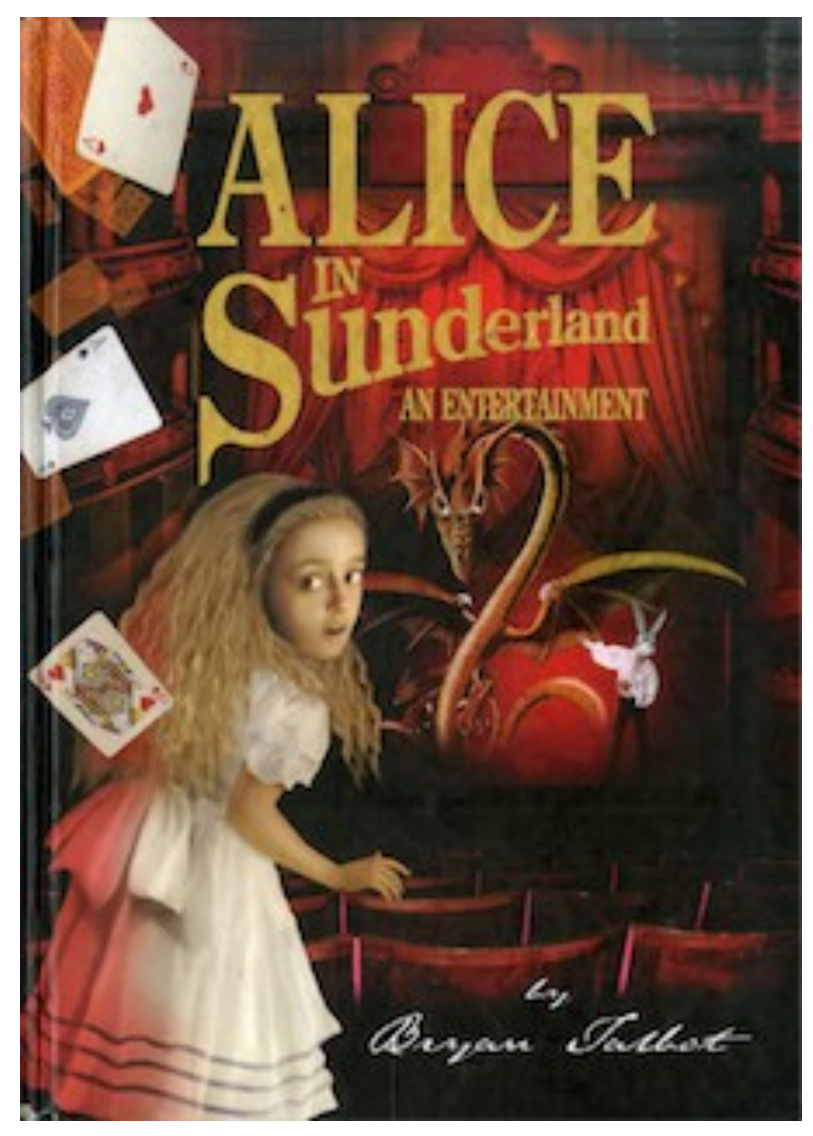

So, I did not approach Bryan Talbot's Alice in Sunderlandwithout high expectations... and my expectations were, appropriately enough, met in a kind of sideways, looking-glass fashion. Whatever I expected, this was not it.

In fact, when approaching this column, I found myself at a loss to how to process the book at all. Generally, I put bookmarks in the pages of whatever I'm working on to mark key passages or panels that illustrate points I want to make. By the time I finished Alice in Sunderland, however, the book was bristling with so many bookmarks that it resembled a hedgehog. A hedgehog one might use for a croquet ball, in fact. Steve Flanagan, whose 7part online review is rendered in the book's own graphic style, admits to a similar predicament: "There's a lot more to the book than I've been able to present here. After all, I have to give this review a manageable structure." So do I... but I found no clearly-delineated thread to pick out from which all the other threads would dangle like a perfectly-parsed sentence. This is not a criticism; I found the experience admirable. This book makes you work hard.

The story begins with a rather dumpy theatre-goer entering the otherwise deserted Empire Theatre in Sunderland, only to be greeted by a White Rabbit delivering the opening speech from Shakespeare'sHenry $V$. The rabbit removes his head to reveal the Performerlike the theatre-goer, as well as several other characters, an avatar of Talbot himself-who becomes a guide to the audience (both within and without the book) on a headlong, complex 
journey through Sunderland's place in the history and culture of... well, not just England, but the world.

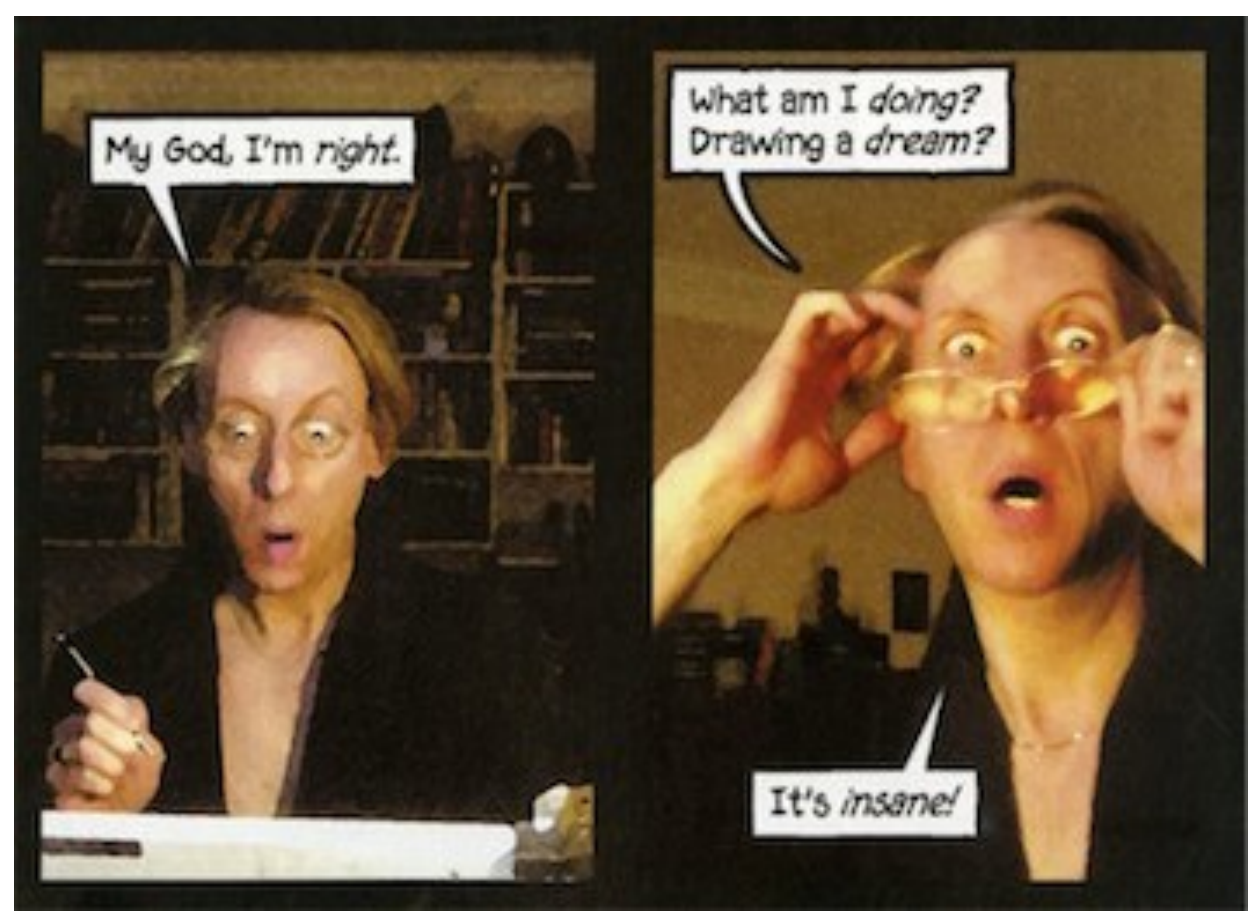

The city of Sunderland becomes likeZelig or Forrest Gump, a character defined by its connection to scores of renowned events. On pages not so much drawn as composed, the story takes so many turns and twists that calling it a trip down a rabbit-hole seems too straightforward; it's more like a guided tour of gopher tunnels, or maybe an ant farm. The narrative slides from one episode to another on the most tenuous of links, like 2-dimensional, visual hypertext; it doubles back on itself so often, and opens so continually from one waking dream into yet another, that the reader can be forgiven for getting as confused and overwhelmed as the characters.

This is, again, not a criticism. Talbot confounds his audience in a way that simulates the Wonderland/Looking-Glass experiences of Alice herself, leaving us never very certain on which level of reality we're currently operating. As the ghost of Sid James notes midway through, even our narrator may not be completely reliable. The reader follows helplessly as the story draws back out of itself to the artist himself, who re-enters the narrative as the Pilgrim... 


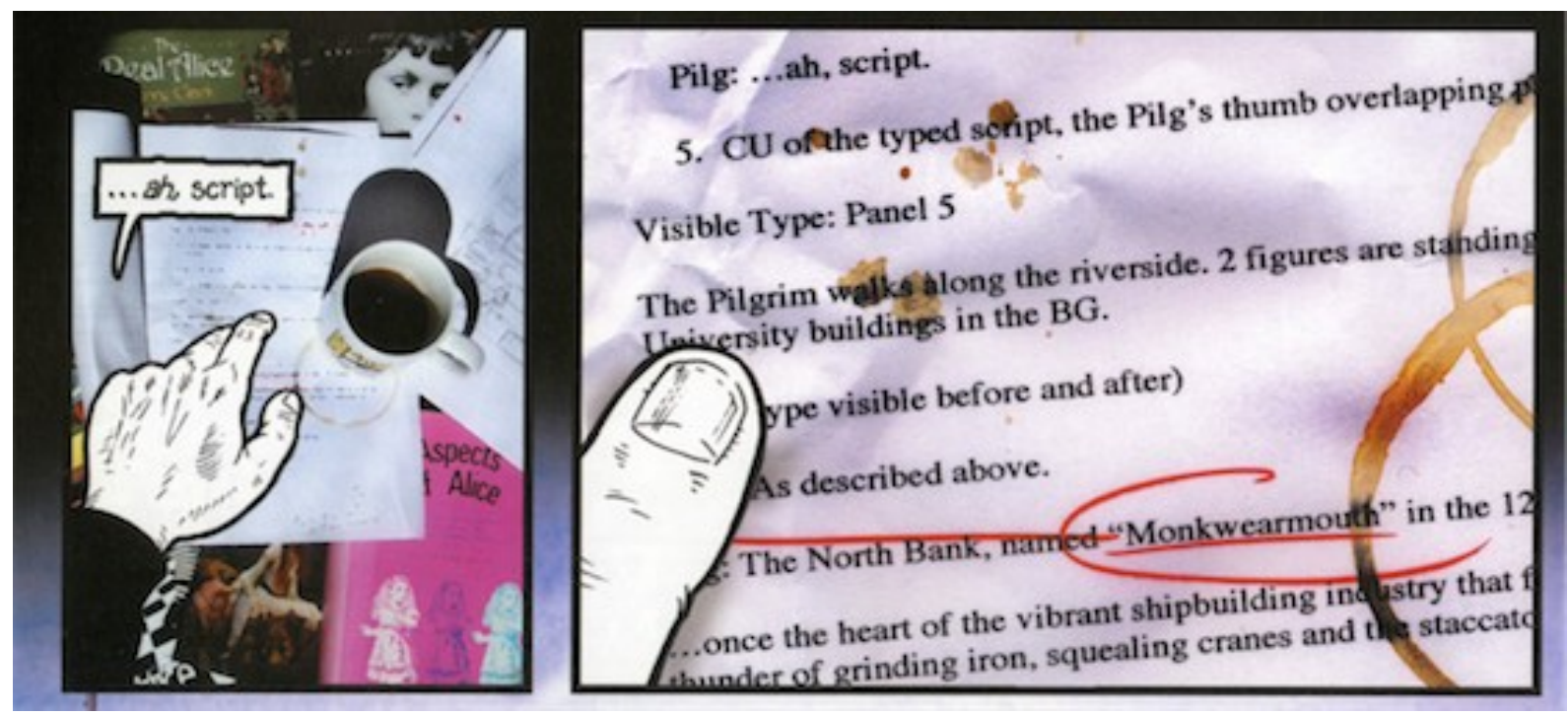

... and who then brings in additional characters, stories, and anecdotes to establish that Sunderland is history and history is Sunderland-and all of it burbles up through Carroll's Alice books like dreams through the subconscious. There is no escaping history in Sunderland, from George Washington toBurke and Hare; from the Venerable Bede to the English music hall tradition. Talbot is steeped in Lewis Carroll, in Sunderland, and in comics, and the book is a mashup of these three elements. The Pilgrim is confronted at one point by a chubby, robed and bespectacled character, whom he addresses as "Venerable Scott McComics-Expert;" sidestories on ghostly stable lads or Moroccan street theatre ordragons take their style from E.C. horror comics or Hergé's Tintin; analyses of the Bayeux Tapestryand Hogarth's Gin Lane and Beer Street serve to illustrate what becomes a sort of apologia for the very art of comics itself. By the time Talbot's connecting his house on St Bede's Street to $B D$, the French abbreviation for comics, you're already pretty deep in his rabbit hole. 


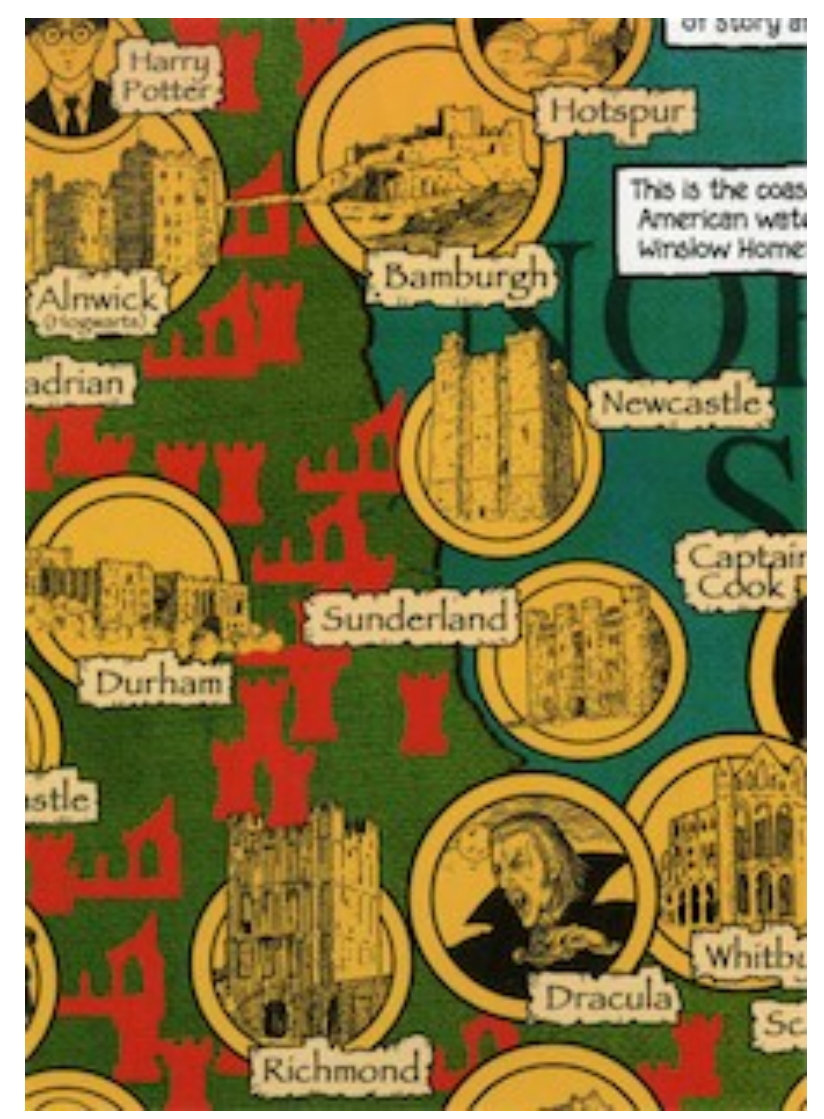

What Talbot has done is to create a kind of homage to Lewis Carroll and the Alice books, and to the city of Sunderland's putative role in Carroll's creative impulses. In so doing, he creates a new definition of place as the sum of history plus culture, seasoned by memory. This notion is made very concrete in the opening pages of the book, where northeastern England is rendered as a patchwork of people and events, honing in later on how Carroll's fantastic topography is discovered in Sunderland's very real contours.

The book is also, to an extent, a lament for what happens when a city turns its back on its history; at one point the Pilgrim observes that Sunderland managed to avoid the worst damage during the Blitz, but now, "where the bombs fail, town planners and big business succeed." Sunderland is in danger of no longer being the sum of its history and culture, making Talbot's effort at bringing it all to the fore that much more crucial. And this introduces an additional element in the stories of Talbot, Carroll, and Sunderland: time.

Time is what produces history and what ratifies culture. Time is a theme in Carroll's work, from the anxious White Rabbit, to the Queen of Heart's accusation that the Mad Hatter is murdering the time, to Carroll's poignant poem at the close of Through the Looking-Glass, in which he touches on the nature of time passing and passed. Talbot plays with time himself by relating all of his stories in the historical present. He deals with time by transcending it, but 
never loses sight of it entirely.

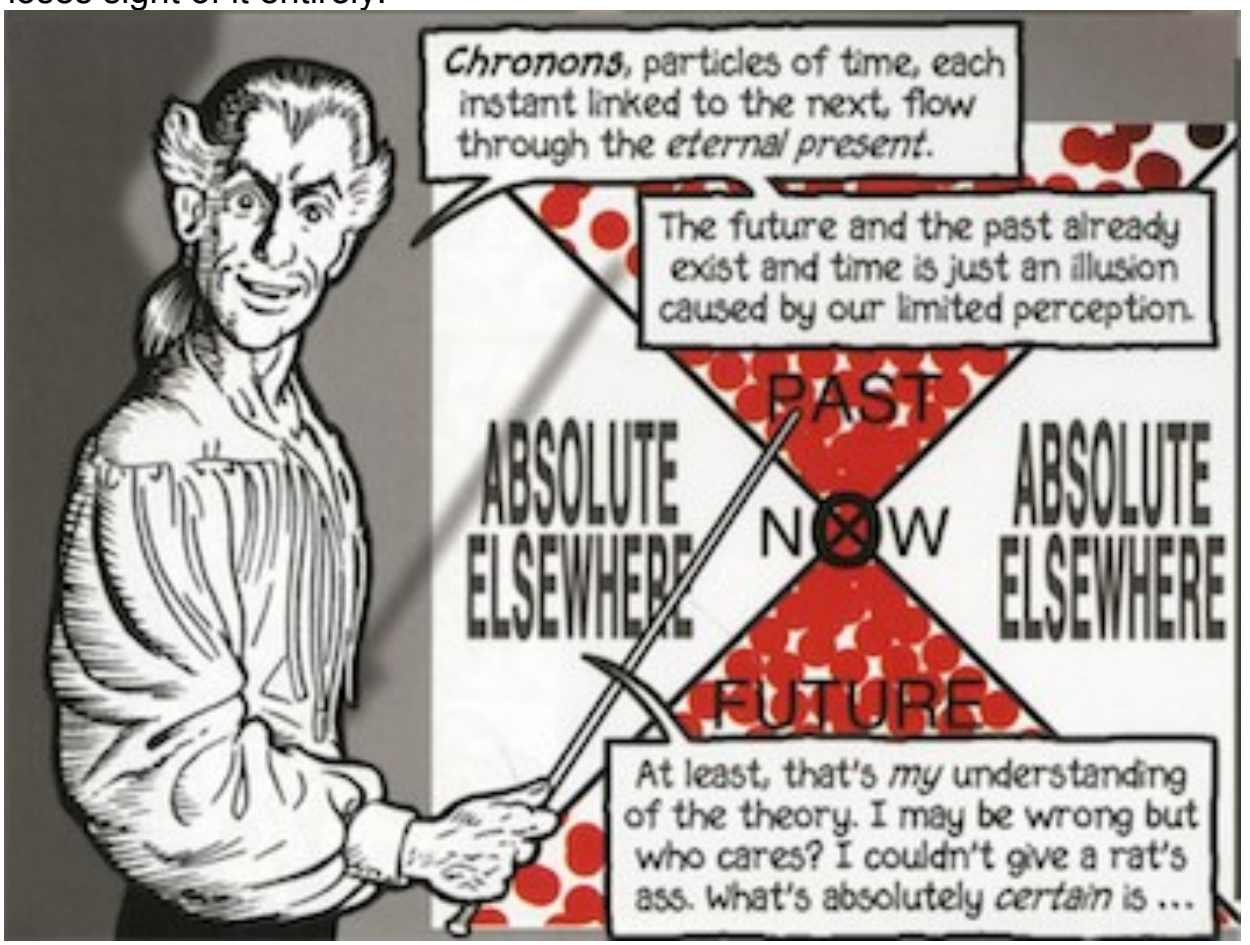

This is the point where I usually present some justification for the scholarly applications of the book in question. But why should I fight to prove the academic quality of Talbot's work? After all: Bryan Talbot's been given an honorary doctorate! From the University of Sunderland! As Talbot pointed out during the degree ceremony, the doctorate is "an indication of the growing recognition of the graphic novel as a respectable vehicle for entertainment, education and communication and the medium itself as a legitimate art form. There's still a lot of prejudice and preconceived notions of what comics are but we're getting there."

That we are. It will take time. According to Book Review Index, Alice in Sunderland was reviewed inSchool Librarian, Library Media Connection, Voice of Youth

Advocates and Booklist. Back in 1960, The Annotated Alice was reviewed in journals such as those as well as in the Chicago Sunday Tribune, The Nation, and the New York Herald Tribune. Morton Cohen's acclaimed 1995 biography of Lewis Carroll was reviewed in the London Review of Books, the New York Revi

ew of Books, The New Statesman, The New Yorker, Victorian Studies, and countless other respectable venues. This seems a little unbalanced to me. Talbot's work is well-researched and creative. Is it relegated to School Librarianrather than the London Review of Books because it's a comic? Because it's perhaps perceived as didactic? Because its bibliography is only 100 items long? Will it get reviewed in the New York Review of Books now that Talbot has an honorary doctorate?

Don't know. For now, Alice in Sunderland appears almost to be a book without a genre which, as in the title of this piece, is a little bit like a riddle without an answer.

On a different front: I'm tremendously honored to have been invited to be a judge for this 
year's Lulu Awards, which recognize the women of the comics world. I have six weeks to determine my nominees for the various Lulu categories, and l'd love to hear from you about women artists, editors, columnists—you name it!—whom you'd hate to see me overlook. Write to me at klg19@columbia.edu with your suggestions!

Images: Alice in Sunderland: an entertainment, by Bryan Talbot, Dark Horse Comics, 2007, pages 185, 94, 10 , and 55.

Karen Green is Columbia University's Ancient/Medieval Studies Librarian and Graphic Novel selector.

Comic Adventures in Academia is (c) Karen Green, 2010 